\title{
(P-10)
}

\section{Diversity of Soil Invertebrate Communities near the Gohagoda Dumping Site and Udawattakele Forest Reserve in Kandy, Sri Lanka}

\author{
T.W.G.F.M. Nijamdeen ${ }^{1 *}$, K.C. Weerakoon ${ }^{1}$, G. Ellepola ${ }^{2}$ \\ ${ }^{I}$ Department of Zoology, Kandy Regional Center, The Open University, Polgolla, Sri Lanka \\ ${ }^{2}$ Department of Zoology, Matara Regional Center, The Open University, Matara, Sri Lanka \\ *fathimamafaziya@gmail.com
}

\begin{abstract}
Soil faunal activity is essential for the functioning of all terrestrial ecosystems. Soil fauna are important in physical and chemical transformation of litter, maintenance of soil fertility and sustained productivity. By-products of human activities affect the proper functioning of the soil fauna with a concomitant decrease in long term soil productivity. The fauna could be used as early indicators of changes brought about in soil properties by pollutants. In Sri Lanka studies of this nature are lacking and even baseline data against which changes could be measured are not yet available. A field experiment was set up in Kandy in two forest areas near the Gohagoda dumping site and the Udawattakele forest reserve area to investigate the soil and leaf litter invertebrates.

The soil invertebrate fauna was extracted in both sampling sites by using $\mathrm{NaCl}$ floatation method and Baermann funnel. The leaf litter invertebrates were extracted using the Tulgren funnel. Collembola, Acarina and Nematoda were the dominant phyla in both forests accounting for more than $80 \%$ of the total individuals. The Udawattakele forest area had the highest taxon and individual numbers of invertebrates. It shows that according to the Tulgren funnel method, Udawattekele area has high species diversity by both Shannon and Simpson indices which is significantly higher $(<0.001)$. The results of Bearmann funnel method showed that it has higher diversity values for Udawattekele than Gohagoda. Overall Udawattekele has a high diversity and evenness than that of Gohagoda area.
\end{abstract}

This comprehensive analysis of invertebrate diversity shows that they may be used as possible indicators of soil quality. They should also be considered as a resource that needs to be properly managed to enhance ecosystem services.

Keywords: Soil invertebrates, Diversity, Gohagoda, Udawattakele 